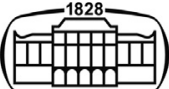

AKADÉMIAI KIADÓ

\title{
A lightweight shelter for the survivors after 2016 earthquake in Accumoli
}

\author{
Asma Gueroui $^{1 *} \odot$, Miklos Halada ${ }^{2}$ and Ehsan Fatehifar ${ }^{3}$
}

\section{Pollack Periodica \\ An International Journal \\ for Engineering and Information Sciences}

16 (2021) 3, 133-138

DOI:

$10.1556 / 606.2021 .00381$

(c) 2021 The Author(s)
${ }^{1}$ Marcel Breuer Doctoral School, Faculty of Engineering and Information Technology, University of Pécs, Boszorkány u. 2, H-7624 Pécs, Hungary

${ }^{2}$ Department of Building Structures and Energy Design, Institute of Architecture, Faculty of Engineering and Information Technology, University of Pécs, Boszorkány u. 2, H-7624 Pécs, Hungary

${ }^{3}$ Department of Building and Environment, Faculty of Education, Arts and Architecture, Danube University Krems, Dr.-Karl-Dorrek-Strasse, 30-3500 Krems, Austria

Received: December 31, 2020 • Revised manuscript received: March 11, 2021 • Accepted: March 22, 2021 Published online: May 26, 2021

\section{ORIGINAL RESEARCH PAPER}

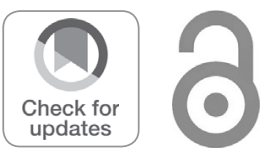

*Corresponding author. E-mail: gueroui.asma@gmail.com

\begin{abstract}
On August 24th, 2016, the town of Accumoli has suffered from a strong earthquake of 6.2 magnitudes, which caused a life loss, destroyed buildings, and huge numbers of homeless people. Now, four years after the earthquake, the village has not yet been reconstructed, no long-term housing has been provided for the inhabitants, and even the rubble of the destroyed houses has not been removed from the site. The significance of this paper is to provide some design scenarios for shelters using wood and membrane as construction materials, in order to provide housing in Accumoli for the existing population in a new site next to the destroyed one. These proposed design projects are part of the consortium of the "Scuola di Ricostruzione di Accumoli".
\end{abstract}

\section{KEYWORDS}

earthquake, temporary shelter, lightweight shelter, membrane and wood shelter

\section{INTRODUCTION}

Central Italy has suffered from three major earthquake events between August and November 2016, which resulted in over 299 deaths, 386 injured, and over 4,800 homeless [1] with huge damage generally to structures and architectural heritage of the Italian districts Abruzzo, Lazio, Marche, and Umbria. The hardest hit were the towns of Amatrice, Arquata del Tronto, and Accumoli.

The town of Accumoli has suffered the highest damages both in terms of human losses and construction damages. The town had its origins in the 12th century when the region was controlled by the Normans and later by the Kingdom of Naples, which make it rich in history, art, and architecture with its medieval and renaissance palaces and churches.

Accumoli is a tourist town with 700 residents' swells in the summer months with tourists to 2,000 residents and more. Unfortunately, due to the earthquake effects, its population has decreased since many of them have moved to live in other cities and villages due to the lack of housing.

Immediately after the earthquake, the Italian government provided tents as emergency relief for people who lost their homes, but these tents are not suitable for all months of the year, especially that the town is situated in the mountain and people will be exposed to the weather conditions, which means that they are not suitable for long residence. Because of the cold, many people preferred to sleep in their cars, while others preferred to rent rooms in hotels or flats in nearby villages. And now, even after years, only a few containers houses were provided. 
This research aims to improve the life quality in the village by providing some ideas of shelters that are cheap, environmentally friendly, and lightweight structures that can be transported and assembled easily by using wood and membrane materials in order to provide housing in Accumoli for the existing population and tourists in a new settlement next to the destroyed village.

\section{APPROACH AND METHODOLOGY}

This research was carried out based on participation in a seminar entitled "Lightweight Architecture made of Membranes and Wood", which was held between 15 and 17 June 2020 , and it was attended by a large number of architects and researchers from different parts of the world who shared their ideas and projects to provide homes for the residents who lost their homes after the earthquake in Accumoli. The seminar goal was to counteract the consequences of the earthquake in Accumoli by constructing temporary houses that are innovative, sustainable, and ecological, and that enables high architectural quality through transparency and lightness by using the strategy finder.pro as a tool that helps to find the best solution [2].

In addition to the seminar results, research papers, and scientific articles that discuss the damages of the 2016 earthquake in Accumoli and Central Italy with a literature review in the field of membrane structure were also collected.

\section{MATERIALS}

The shelter design must be environmentally friendly, light enough to be transported, installed, and removed easily at a low cost. And the best materials to achieve this are wood and membrane (fabric).

\subsection{Wood}

Wood is an excellent abundant, renewable, recyclable, and local natural material. Wood materials have numerous advantages over other construction materials: their manufacturing is simple, clean and it can enable developers to build more quickly and cheaply. Wood combines relatively high mechanical strength with low weight, which makes the structure strong, durable, and resilient. This material is good for the building, good for the environment.

\subsection{Membrane}

Membranes are thin and flexible surfaces that usually refer to façade or roof skins that carry loads primarily through tensile stresses.

During the last decades, lightweight membrane structures have become a popular method of construction in Europe and also in the United States of America. Names like Frei Otto, Stromeyer, and Walter Bird are synonymous with membrane structures. Their exploratory work in this field has been significant in the promotion of membrane structures in many countries of the world [3].

Membranes are great for temporary use: they are very quick and easy to install, uninstall, and to be reconfigured, they need low maintenance compared to other materials. Membrane materials used for roof structures in buildings have a comparatively low thermal isolation ability compared to traditional building materials.

\section{DISCUSSION OF THE PROJECTS AND CASE STUDIES}

\subsection{The sphere house by Ehsan Fatehifar}

4.1.1. The project description. The pavilion in Fig. 1 is a two-story compact building, which is covered with fabrics. It is a basic idea, which aims to integrate the dwelling with the greenhouse. The time estimation for installation is $3-4$ days due to prefabricated parts:

- The convex form prevents a high snow load;

- The material transparency of some segments is different;

- At the top photovoltaic panels form the upper cap;

- Two segments of the wooden structure are rotatable connecting the interior to the landscape;

- It is also possible to rotate them separately.

4.1.2. The project properties. The pavilion has several properties that make it unique:

- Lighting system: These units are connected to each other which enables them to act as a lighting system that shapes the background for a future amphitheater;

- Paintings: There is a painting on one side of each unit that turns this area into an exhibition;

- The area: the sphere has an area of 90 square meters (each story is around $45 \mathrm{~m}^{2}$ ). The highest point elevation is $9 \mathrm{~m}$;

- Ventilation: the ventilation would be part natural and also Heating, Ventilation, and Air Conditioning (HVAC) system includes ceiling fans and portable heater.

\subsection{The rectangular apartment by Halada Miklos}

4.2.1. The project description. This project is two different floor plan variations, which are covered with fabrics.

It is a basic idea, which aims to integrate the dwelling with the greenhouse.

The pavilion in Fig. 2 is two different prototypes of apartment units, the first one is a four-bed apartment (2 bunk beds) and the second one is a double-bed apartment.

4.2.2. The project properties. The apartment is built out of glulam beams and cross-laminated timber wall panels. The natural ventilation works thru the floor, windows, and roof (as it is shown in Fig. 3). 
a)

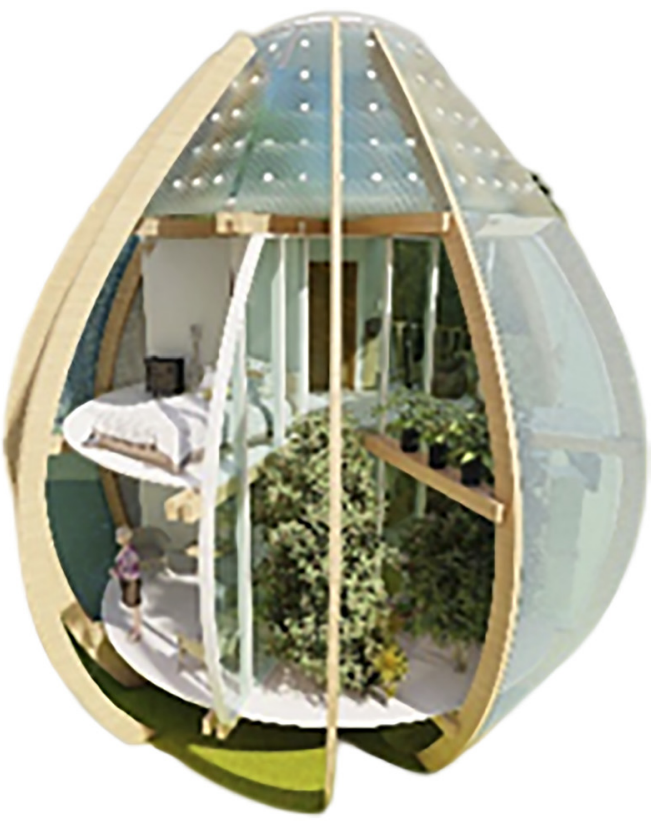

b)

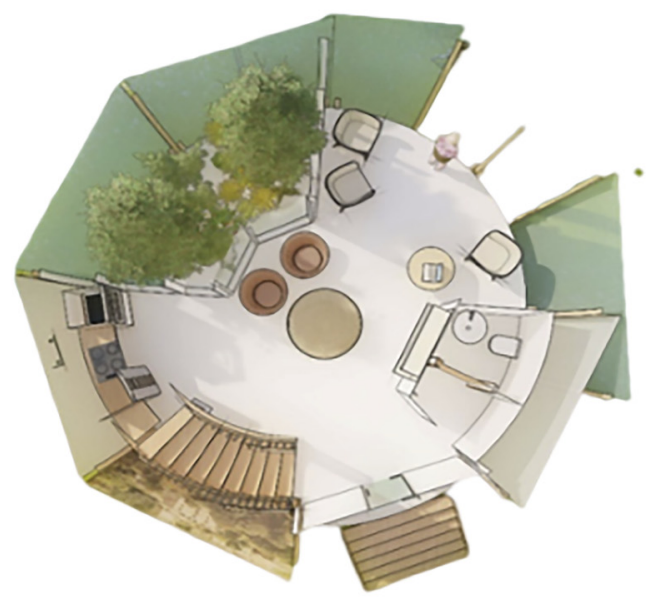

c)

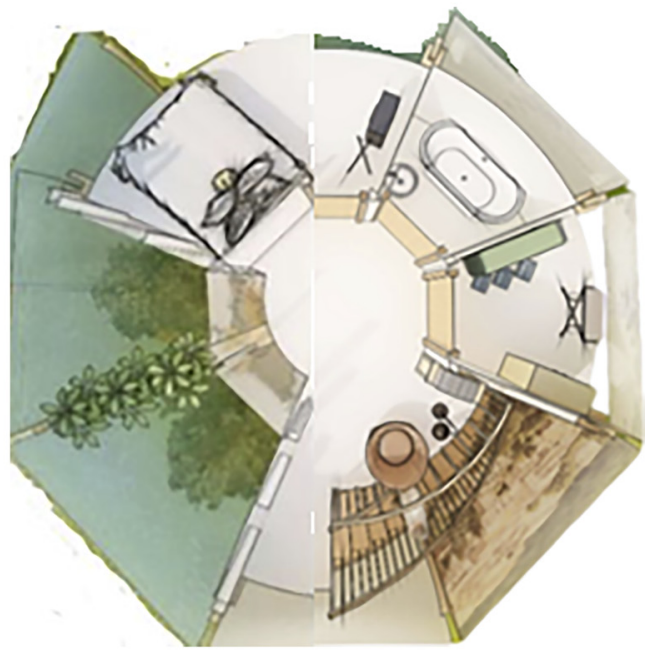

Fig. 1. The sphere by Ehsan Fatehifar (Source: co-author's design, [4]) a)
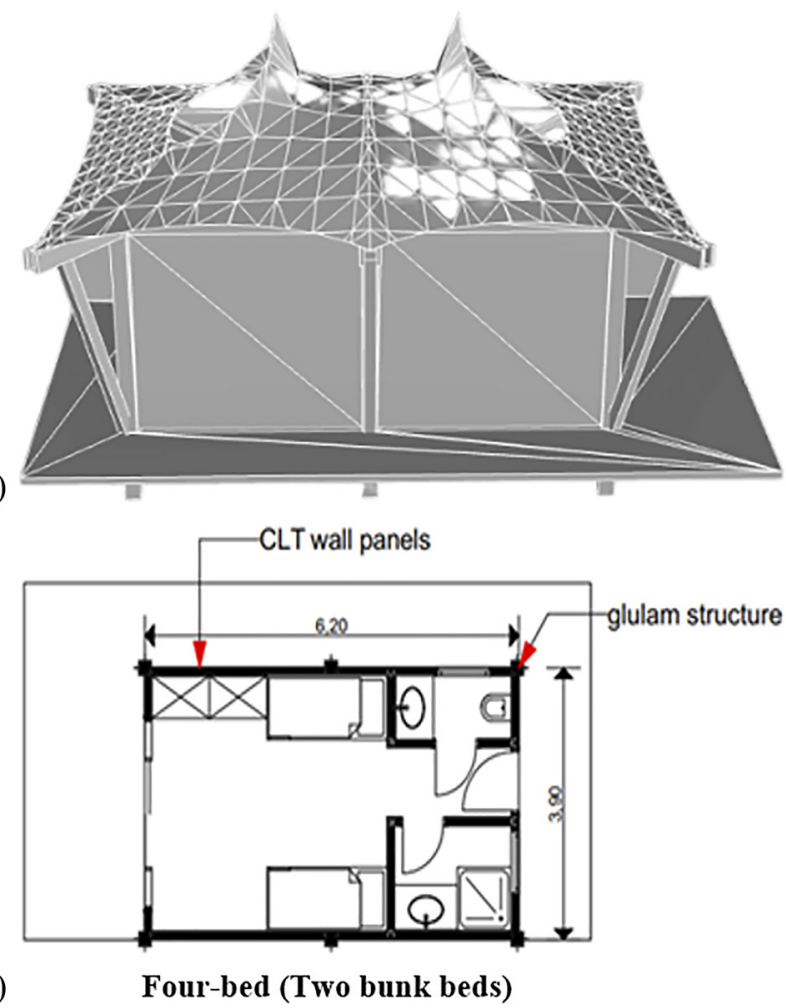

b)

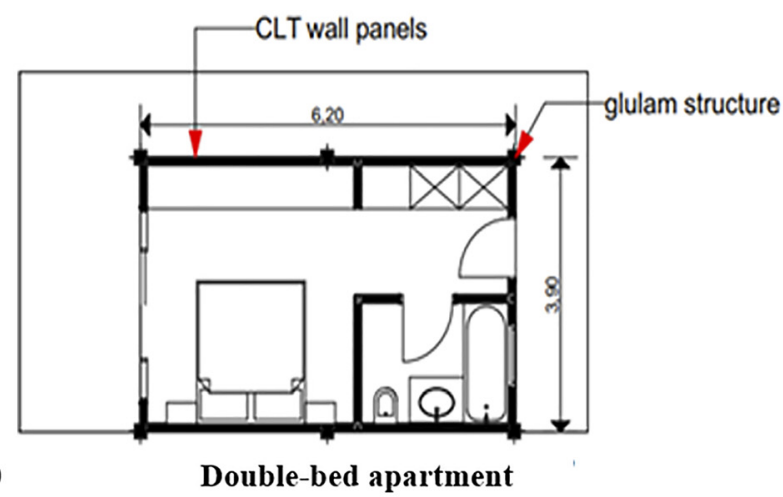

Fig. 2. The pavilion by Miklos Halada

(Source: co-author's design, [5])

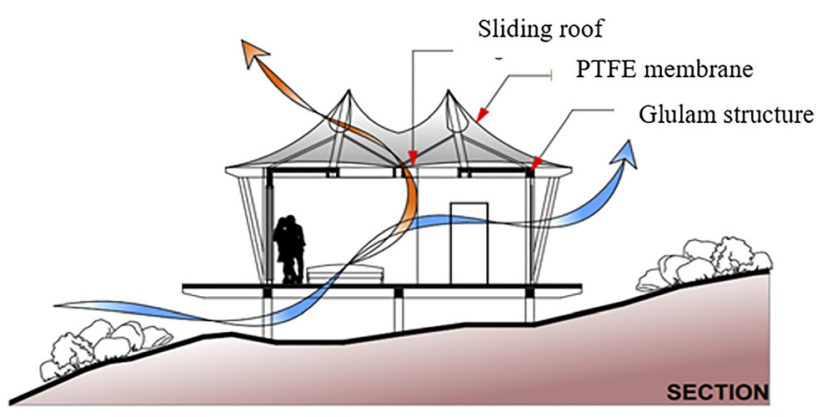

Fig. 3. The natural ventilation system by Miklos Halada (Source: co-author's design, [5]) 


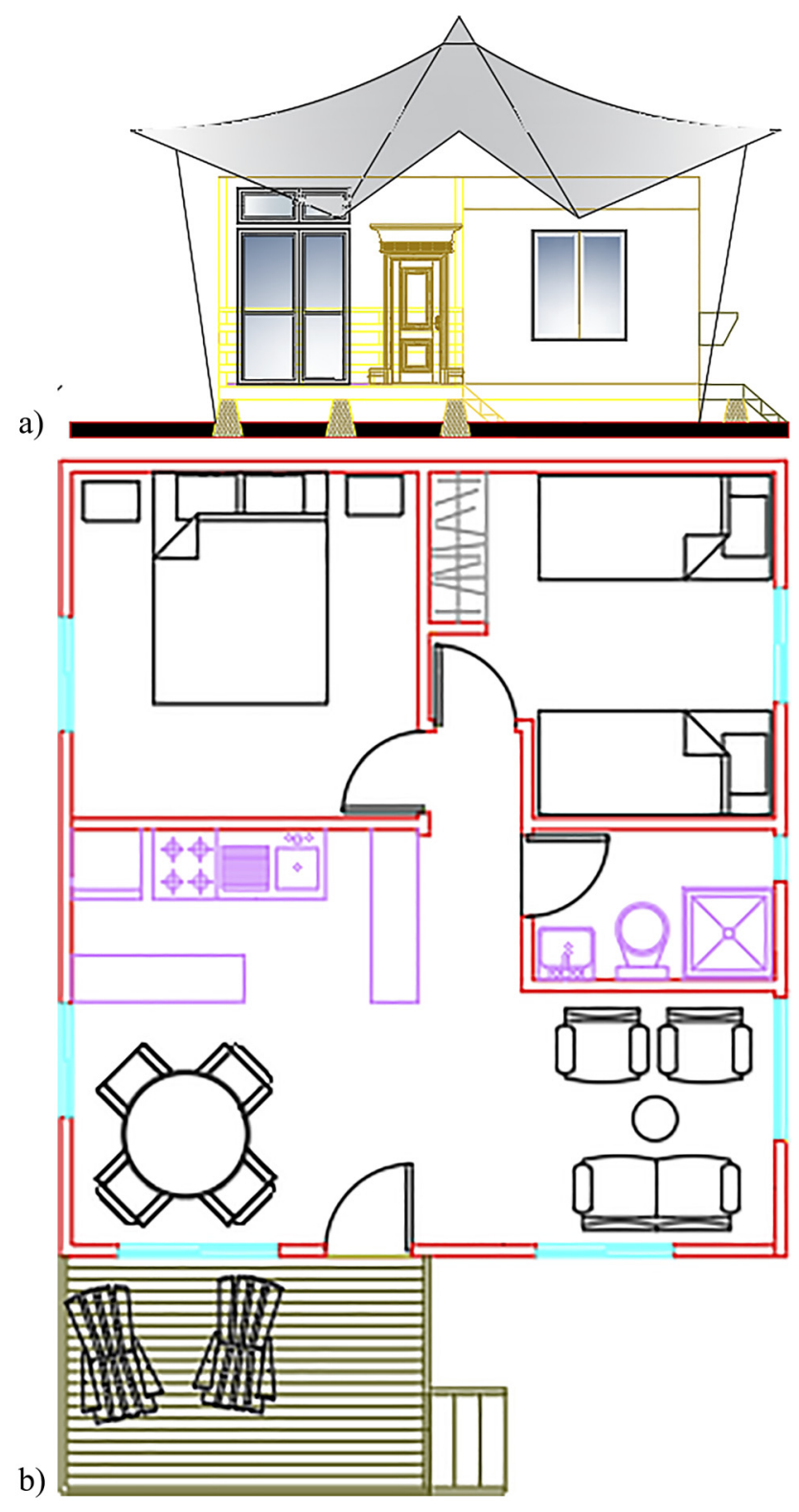

Fig. 4. The façade of the pavilion by Asma Gueroui (Source: the main author's work)

\subsection{The square house by Asma Gueroui}

4.3.1. The project description. The pavilion in Fig. 4 is a one-story building, which is covered with fabrics. It is designed for a number of six people. It is a basic idea, which aims to integrate the dwelling with the greenhouse.

This pavilion has two bedrooms, the first one is a fourbed bed-room and the second one is a double-bed bedroom with a big living room.

4.3.2. The project properties. The natural ventilation is presented by the orientation of the project the floor, the doors, windows, and the roof as it is shown in Fig. 5.

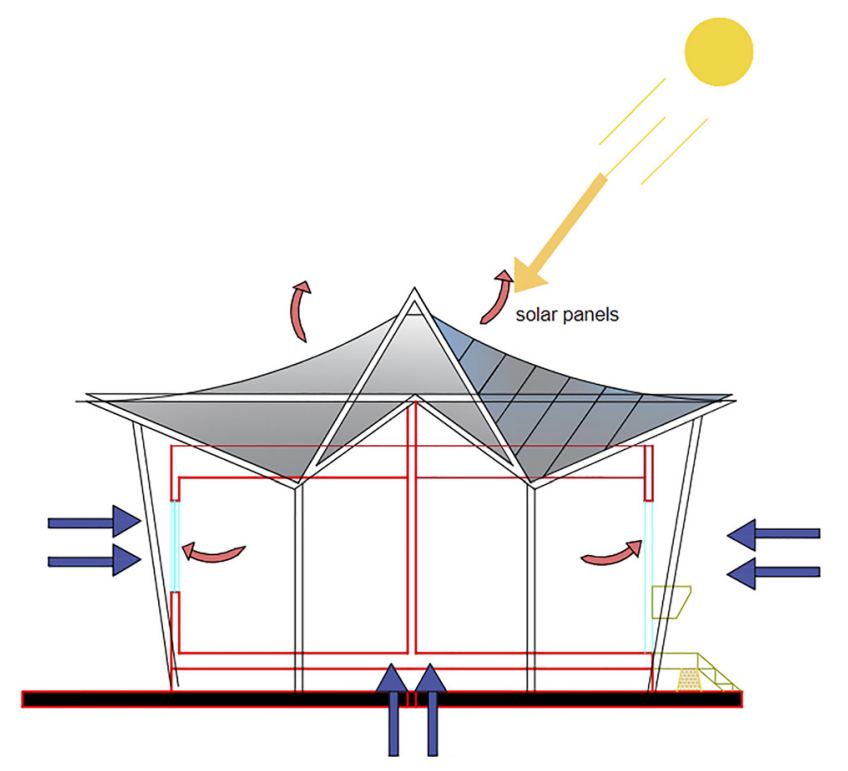

Fig. 5. The natural ventilation of the pavilion by Asma Gueroui (Source: the main author's work)

\section{DISCUSSION}

The 2016 earthquake destroyed the buildings of Accumoli and other towns in the Central Apennines, which is one of the most seismically active areas in Italy. This earthquake is not the first in the zone and it certainly will not be the last [6].

This paper is intended to suggest some design ideas for eco-friendly shelters for housing the existing population and attracting tourists to the village because the provided and existing types of shelters are not appropriate for long-term living.

Also, this study aims to develop the methodological design of a shelter that can be turned into a permanent house [7], by using local materials and community participation [8].

\subsection{The provided projects by the Italian governmental}

Tents (Fig. 6 in Table 1) are the most common form of temporary houses used in emergency relief; they are good as a rapid response because they are typically stockpiled as part of disaster preparedness plans in many countries, they have a light nature, which makes them easy to install and uninstall and to be transported. But tents are not appropriate for long-term residence because they provide poor quality of life and less likelihood of basic facilities. Also, the people in tents are deprived of all privacy and constantly exposed to the weather elements (rain, cold, wind). Moreover, they are not environmentally friendly. Unfortunately, what could be a great efficient way of managing a disaster now becomes a crisis with so many negative consequences that would require a lot of investment and planning to deal with.

A few months after the earthquake, the government provided shipping containers (Fig. 7 in Table 1) to the survivors, which are more comfortable than tents, they were designed to resist hard weathering and heavy loading over long-distance transportation. But unfortunately, its 
Table 1. A comparative study between the proposed ideas and the provided shelters by the government

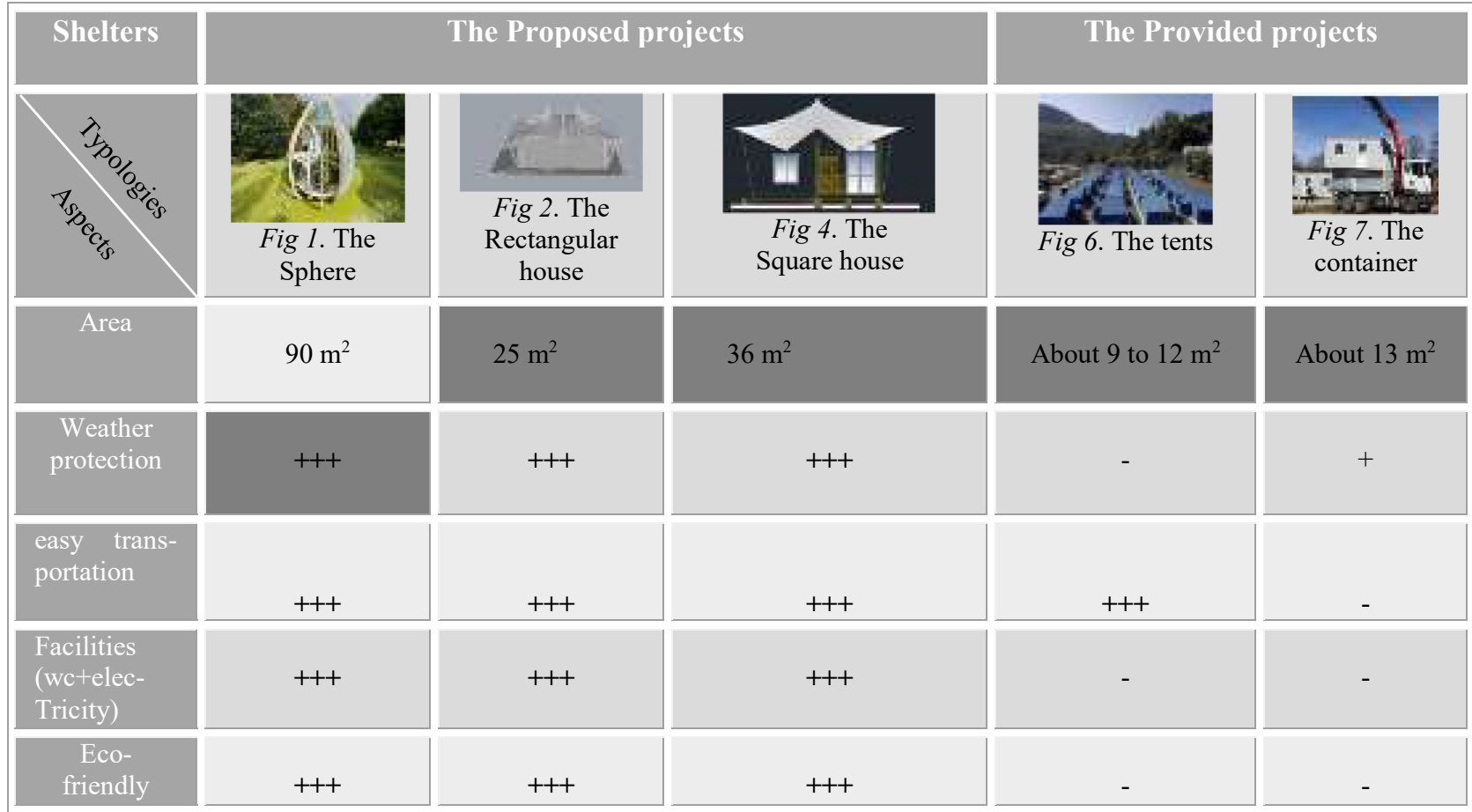

transportation is hard and costly as all the prefabricated construction (as mentioned in the table below).

\subsection{The proposed projects}

The three projects are environmentally friendly, easy to mantle and dismantle, need low transportation cost due to the use of local materials. These types of shelters are extremely economical and allow survivors to be housed for a long period, they are more permanent than other temporary shelters which have a very limited life span and tend to fail when used as a long-term solution (Table 1).

The square house in Fig. 4 is designed for a big family. It is good for families who like simplicity in their lifestyle and their homes. These houses are very similar to wooden mountain traditional houses with a slight difference, which is the use of the membrane as a roof (Table 1).

While the rectangular house is designed for four or two persons, it is a simple design that can be used as a shelter for tourists or small families and couples and the sphere house in Fig. 1 features a modern design, a beautiful view, and is easy to assemble and disassemble (as mentioned in Table 1).

These projects in Table 1 are just opinions and suggestions that need to be modified and developed to solve the homeless problem in Accumoli.

\section{CONCLUSION}

This study explores the future possibilities for a shelter by applying the knowledge in light structures and local resources in emergency scenarios where wood should be used as a locally available resource and as a material that create a connection between the human and the environment.

Due to climate changing, it is predicted that disasters will continue to happen and as a consequence, the demand for temporary housing will still exist too. Therefore, more research on wood and membrane house for shelter purposes should be done to fully utilize their potential and improve its shortcoming, also. Investigation in more different forms and shapes that could be easily constructed for temporary conditions to give a variety to integrate into different sites and allow the community participation is needed.

\section{ACKNOWLEDGEMENTS}

The authors would like to thank all the partners of "the lightweight architecture made of Membranes and Wood Seminar". Thanks to all of the involved in this event, particularly the organizers from the Danube University Krems, Department of Building and Environment, with special thanks to Dr. Robert Roithmayr for his kindness and help.

\section{REFERENCES}

[1] Protezione Civile, Italian Department of Civil Protection, 2016. [Online]. Available: http://www.protezionecivile.gov.it/attivita- 
rischi/rischio-sismico/emergenze/Centro-Italia-2016. Accessed: Dec. 25, 2020.

[2] Lightweight architecture made of membranes and wood, Seminar, 2020. [Online]. Available: https://www.donau-uni.ac.at/en/ university/events/lightweight-architecture-made-of-membranesand-wood0.html. Accessed: Dec. 30, 2020.

[3] A. P. L. Fiúza, "Polymeric membranes is architecture," MSc Thesis, Instituto superior Tècnico, 2016.

[4] Membranes. [Online]. Available: https://membrane.online/project/ 499. Accessed: Dec. 30, 2020
[5] Membranes. [Online]. Available: https://membrane.online/project/ 501. Accessed: Dec. 30, 2020.

[6] Italy Earthquake Response and Recovery: A Disaster Response Case Study, GSMA, 2017.

[7] D. Ravina and R. R. Shih, "A shelter for the victims of the typhoon Haiyan in the Philippines: the design and methodology of construction," Pollack Period., vol. 12, no. 2, pp. 129-139, 2017.

[8] D. Ravina and R. R. Shih, "Ocho Balay: Design of a permanent typhoon shelter for the rural areas in the Philippines," Pollack Period., vol. 15, no. 2, pp. 221-232, 2020. 